\title{
Icesave, Finanzkrise und Demokratie: Der Fall Island(s)
}

\section{Meike Stommer}

We have forgotten that there are two pillars in the western heritage that we are proud of. One is the evolution of the free market but the second is the evolution of democracy. [...] And what I did was when I was faced with a decision between the financial concerns on the one hand, and democracy on the other, I decided to go with democracy. ${ }^{1}$

Der Vulkanausbruch des Eyjafjallajökulls im Mai 2010 machte Island, die kleine Republik im Nordatlantik mit ihren knapp 320000 Einwohnern, zum zweiten Mal in wenigen Jahren besonders präsent in den internationalen Medien. Die Aschewolke des Vulkans behinderte tagelang den internationalen Flugverkehr und führte zu zahlreichen Flugausfällen mit hohen Kosten für die Flugindustrie.

Die erste große Präsenz erfolgte 2008, als das Land zum Symbol der internationalen Finanzkrise wurde. Im Oktober 2008 brach das isländische Bankensystem zusammen, was nahezu zu einem Staatsbankrott führte. Die Schreckensmeldungen in diesem Zusammenhang machten das Land auch zu einem Thema für die Wissenschaft, die beispielsweise internationale wie nationale Auswirkungen der Krise beleuchtet. Bis dahin war das Land eher selten ein Thema. In der (deutschen) Politikwissenschaft wurde die Untersuchung von kleinen Staaten wie Island größtenteils ignoriert.

Im Folgenden werde ich zunächst auf die Situation des Landes vor der Krise eingehen. Im Mittelpunkt des vorliegenden Artikels stehen die Auswirkungen der Krise auf Island - insbesondere beleuchtet wird hier die erstarkte Demokratiebewegung im Land. Bedeutend sind in diesem Zusammenhang die IcesaveKonten und das erste Referendum in der Geschichte der isländischen Republik. Der Artikel endet mit der Betrachtung jüngster Entwicklungen im Land.

\section{A. Island vor der Krise: Demokratie und Wohlstand}

Die isländische Entwicklung war lange eine Geschichte der Distanz und der Isolation. Island liegt am äußersten Rand Europas. Nicht zuletzt deshalb ist das Land kulturell ungewöhnlich homogen, mit einer eigenen, relativ einheitlichen Sprache und einer fast einheitlichen Religion. Zu Beginn des 20. Jahrhunderts

1 Ólafur Ragnar Grímsson, [Präsident Islands] 2010, zitiert nach A. Lorie, Iceland president: We are being bullied (30. Januar 2010; www.edition.cnn.com, 10. Mai 2010). 
war Island noch eines der ärmsten Länder der Welt. Bis dahin war das Land fast unbeeinflusst von Industrialisierung und Urbanisierung, „basically a development country that had been by-passed by the industrial revolution". ${ }^{2}$

Etwa seit dem Ende des Zweiten Weltkriegs beschritt Island einen grandios erfolgreichen Weg zu einem der reichsten Länder der Welt. Insbesondere im Zeitraum von 1960 bis 1980 erlebte das Land eine Zeit des wirtschaftlichen Aufschwungs. Im Jahr 1980 stand das Land an zweiter Stelle auf der Liste der Vereinten Nationen der Länder mit den besten Lebensstandards (Human Development Index). ${ }^{3}$ In den 1990er Jahren wurde die Wirtschaft des Landes liberalisiert und privatisiert.

Bis zur Finanzkrise führte Island eine Reihe internationaler Statistiken an: Dort lebten die glücklichsten Menschen, sie hatten eine der höchsten Lebenserwartungen und eine der besten Geburtenraten in Europa. Es gab ein hohes ProKopf-Einkommen und ein hohes Wirtschaftswachstum, Arbeitslosigkeit war real nicht existent. 2007 hatte das Land schließlich den ersten Platz auf der Liste der Vereinten Nationen erlangt. ${ }^{4}$

Die isländische Hauptstadt Reykjavík, in deren Großraum heute zwei Drittel aller Isländer leben, genoss (auch) ihr Ansehen als die Party-Metropole Europas. Die „,neue Generation der Wikinger“ flog in ihren Privatjets durch die Welt und kaufte ein Unternehmen nach dem anderen - darunter auch den britischen Fußballclub West Ham United - oder flog kurzerhand Elton John zu einer Geburtstagsparty ein. Erst viel später stellte sich heraus, dass viele dieser Transaktionen durch unsichere Kredite allzu entgegenkommender Banken finanziert worden waren. ${ }^{5}$

2 H. Ásgrimsson, Why Small States must Think Big. Eröffnungsrede anlässlich des Workshops on Small States, 17./18.9.2004, University of Iceland (www.eng.forsaetisraduneyti.is/minister/speeches_HA/nr/1517, 17.3.2005); vgl. auch G.H. Kristinsson, From Home Rule To Sovereignty: The Case Of Iceland, In: G. Baldacchino/D. Milne (Hrsg.), Lessons From the Political Economy of Small Islands: The Resourcefulness of Jurisdiction, London 2000, S. 141 (143).

3 Vgl. S. Ólafsson, Íslenska efnahagsundrið: Frá hagsæld til frjálshyggju og fjármálahruns [Das isländische Wirtschaftswunder. Von Wohlstand zu Liberalismus und Finanzkollaps], Stjórnmál og stjórnsýsla 4 (2008), 231 (234). In den Index geht neben Lebensstandard und Bildung die Lebenserwartung ein. Alle Übersetzungen sind von der Autorin selbst vorgenommen.

4 Die Geburtenrate lag 2008 bei 2,14, die Arbeitslosenquote schwankte vor der Finanzkrise um etwa 1 Prozent, gleichzeitig gab es eine Menge offener Stellen, die nicht besetzt werden konnten, vgl. Hagstofa, Mannfjöldi [Bevölkerung]/Atvinnupátttaka [Arbeitsmarkt] (www.hagstofa.is, 3.7.2010); s.a. Kristinsson, Sovereignty (Fn. 2), S. 141 ff.

5 Vgl. R. Boyes, Meltdown Iceland: How the Global Financial Crisis Bankrupted an Entire Country, London 2009, S. 1 ff. 
In Island ist man stolz auf die lange parlamentarische Tradition. Das im Jahr 930 gegründete Alpingi gilt als das älteste noch aktive Parlament der Welt. Ab 1262 stand Island unter der norwegischen Krone und schließlich ab 1380 gemeinsam mit Norwegen unter der dänischen Krone. Auf diese Weise verlor das Alpingi stetig an legislativer Bedeutung, bis schließlich 1662 der dänische König vollständig die Macht übernahm. 1800 wurde das Alpingi aufgelöst, bereits 1845 aber von Dänemark zunächst als rein konsultative Institution wieder ins Leben gerufen. 1830 begann der lange, hartnäckige und friedliche isländische Unabhängigkeitskampf gegen Dänemark. Erste Erfolge hatte dieser Kampf 1904 mit Erlangen der Selbstverwaltung. Im Jahre 1918 wurde Island ein souveräner Staat, blieb aber in einer Union mit Dänemark unter der dänischen Krone. Die vollständige Unabhängigkeit erlangte das Land (erst) 1944 mit Gründung der Republik. $^{6}$

Island hat eine konstant hohe Wahlbeteiligung. Das Land landet beim IDEARanking aller Länder mit einer durchschnittlichen Wahlbeteiligung bei nationalen Parlamentswahlen von 89,5 Prozent seit 1945(-1998) auf dem vierten Platz. ${ }^{7}$ Eine Besonderheit des isländischen politischen Systems liegt in seiner Kleinheit und der sich daraus ergebenen Nähe: Isländische Politik ist ungewöhnlich offen, persönlich und von unberechenbarer Natur. ${ }^{8}$ Vieles wird unbürokratisch geregelt und ist mit analytischen Mitteln wie z.B. einer Organisationstheorie nicht ohne weiteres greifbar. Das Verhältnis zwischen Gesellschaft und politischem System ist durch eine enge und stabile Beziehung charakterisiert. Die Verbindungen sind personalisiert, jeder kennt jeden, es geht „familiär“ zu, Politikerpersönlichkeiten sind leicht zugänglich. ${ }^{9}$ Isländer haben ein intimes Wissen der finanziellen Situation der anderen, ihrer familiären Verbindungen und ihres persönlichen Lebens. „All politics, since the days of the first Althing session in 930, have the flavor of a town meeting. “10 Die Personalität des Systems zeigt sich auch in Wahlkämp-

6 Vgl. zur isländischen Geschichte G. Karlsson, Iceland's 1100 Years: History of a Marginal Society, London 2000.

7 Zum Vergleich: Deutschland ist hier auf dem 22. Platz mit 80,6 Prozent, vgl. IDEA, Turnout in the World: Country by Country Performance (www.idea.int, 30.5.2006).

8 Vgl. A.J.K. Bailes/D.F. Gylfason, „Societal Security“ and Iceland, in: A.J.K. Bailes (Hrsg.), Through European Eyes. An Anthology of Speeches by Alyson J.K. Bailes, Reykjavík 2009, S. 143 (161).

9 Beispielsweise hat bei der so genannten Fischmehl-Krise ein betroffener Exporteur die Telefonnummer des Außenministers aus dem Telefonbuch herausgesucht und ihn abends zu Hause angerufen, um ihn über die Geschehnisse zu informieren, vgl. dazu B. Pórhallsson/E. Ellertsdóttir, The Fishmeal Crisis, in: Á.E. Bernharðsdóttir/L. Svedin (Hrsg.), Small-State Crisis Management: The Icelandic Way, Stockholm 2004, S. 91 (113).

10 M.T. Corgan, Iceland and its Alliances: Security for a Small State, Lewiston 2002, S. 139. 
fen: Diese sind von persönlichen Rivalitäten geprägt und machen sich mehr an einzelnen Politikerpersönlichkeiten und ihrer Erscheinung fest als an der Parteimitgliedschaft.

Being a small parliament, it is able to allow individual parliamentarians considerable scope for manoeuvre, and it interferes more with the activities of the executive than most European legislative assemblies, irrespective of the government of the day. ${ }^{11}$

Kleinen Demokratien sagt man einen Hang zu pragmatischen Lösungen und Kompromissbereitschaft nach. Das isländische politische System ist nicht durch Korruption oder andere illegale Praktiken gekennzeichnet, die Kleinheit des Landes und damit der Elite unterstützen aber begünstigende Vereinbarungen untereinander. Soziale Bewegungen und Bürgerinitiativen sind nicht Teil der politischen Kultur, sie verschwinden meist schnell wieder von der Bildfläche, viele Streitpunkte werden gleich im etablierten Parteiensystem ausgehandelt. Island ist durch eine auffallende Seltenheit außerparlamentarischer Aktionen gekennzeichnet. ${ }^{12}$ „Im Allgemeinen sind die Isländer pragmatisch, mehr damit beschäftigt Geld zu verdienen als Prinzipien zu diskutieren. “13 Eingebettet in eine politische Kultur des Konsenses, besteht in Island generell ein geringes Interesse an Prinzipiendiskussion. „Die Demokratie in Island [wird] verehrt, aber man spricht hier nicht so viel darüber wie in den anderen nordischen Ländern. “14

In Island gibt es eine starke Tradition der repräsentativen Demokratie. Die Macht des Parlamentes wird im politischen System unterstrichen. Laut der isländischen Verfassung kommt es in drei Fällen zu einer Volksabstimmung:

- wenn drei Viertel der Parlamentsmitglieder vor abgelaufener Wahlperiode den Präsidenten von der Macht ablösen möchten (Artikel 11);

- wenn der Präsident sich weigert, ein vom Parlament verabschiedetes Gesetz mit seiner Unterschrift zu ratifizieren (Artikel 26);

11 G.H. Kristinsson, Political Developments, in: J. Nordal/V. Kristinsson (Hrsg.), Iceland The Republic. Handbook Published by the Central Bank of Iceland, Reykjavík 1996, S. 122 (126); s.a. Corgan, Iceland (Fn. 10), S. 140.

12 Vgl. F. Rubart, Auf Stimmenfang im Nordatlantik: Parteiensystem und politische Macht in Island, 2004, S. 43 f. So gibt es neben den Protesten im Zuge der Finanzkrise nur einige wenige Beispiele, bei denen es zu heftigen Protesten in Island gekommen ist: gegen eine NATO-Mitgliedschaft, gegen das Verteidigungsabkommen mit den USA sowie gegen eine EFTA-Mitgliedschaft.

13 G.H. Kristinsson 2004, zitiert nach ebd., S. 4.

14 Ebd. 
- wenn der 62. Artikel der Verfassung geändert werden soll, in dem die evangelische Kirche als Staatskirche festgelegt ist (Artikel 79; alle anderen Verfassungsänderungen liegen im Machtbereicht des Parlamentes). ${ }^{15}$

Das Ergebnis einer solchen Volksabstimmung ist für die Regierung bindend. Parlament oder Regierung können weitere Volksabstimmungen ansetzen, diese haben dann aber nur eine beratende Funktion. Ein allgemeines Gesetz über Volksabstimmungen, deren Durchführung und Durchsetzung wurde erstmals im Juni 2010 verabschiedet. ${ }^{16}$

Das isländische Parteiensystem war jahrzehntelang von der konservativen Unabhängigkeitspartei dominiert. Seit ihrer Gründung 1929 hat die Unabhängigkeitspartei bis zum Regierungsrücktritt 2009 und der darauf folgenden Wahl, in der sie nur knapp 23 Prozent erreichte, konstant etwa 40 Prozent der Stimmen auf sich vereint. Eine Zwei-Parteien-Regierungsbildung war bis dahin seit den dreißiger Jahren ohne diese Partei nicht möglich. Von 1944 bis 2008 war sie 54 Jahre lang an der Regierung beteiligt und stellte 43 Jahre den Ministerpräsidenten. ${ }^{17}$ Nach dem Ende des Kalten Krieges war sie von 1991 bis 2009 an der Regierung beteiligt, zunächst mit den Sozialdemokraten, von 1995 bis 2007 mit der Fortschrittspartei, dann wieder mit den Sozialdemokraten bis zum Regierungsrücktritt im Zuge der Finanzkrise. Von 1991 bis 2004 war ihr damaliger Parteivorsitzender, Davíð Oddsson, Ministerpräsident Islands und damit in der Geschichte des Landes der am längsten amtierende Ministerpräsident. ${ }^{18}$

Die konstante Dominanz der Konservativen ging einher mit einer Schwäche der Sozialdemokraten, die in der zweiten Hälfte des 20. Jahrhunderts nur durchschnittlich 14 Prozent der Stimmen auf sich vereinen konnten. Aufgrund dieser

15 Vgl. Stjórnarskrá Íslands [Die Verfassung Islands] 1944; s.a. G.H. Kristinsson, Próun íslensku stjórnarskrárinnar [Die Entwicklung der isländischen Verfassung], Reykjavík 1994, S. 55.

16 In den anderen nordischen Ländern werden gelegentlich solche ratgebenden Volksabstimmungen abgehalten, wie beispielsweise zweimal in Norwegen um die Mitgliedschaft des Landes in der Europäischen Gemeinschaft (1972/1994). Das Ergebnis solcher Volksabstimmungen wird im Allgemeinen von den Regierungen akzeptiert, vgl. ebd., S. $55 \mathrm{f}$.

17 Vgl. O.P. Harðarson/G.H. Kristinsson, Iceland, EJPR 38 (2000), 408 (415ff.); O.P. Harðarson, Iceland, in: G. E. Delury (Hrsg.), World Encyclopedia of Political Systems and Parties, New York 1999, S. 473 (476); G.P. Eythórsson/D. Jahn, Das politische System Islands, in: W. Ismayr (Hrsg.), Die politischen Systeme Westeuropas, 2009, S. 195 (200 f.).

182002 war er im gesamteuropäischen Vergleich der am längsten amtierende Anführer einer Regierung sowie einer der wenigen Mitte-rechts-Ministerpräsidenten, vgl. B. Dórhallsson, The Skeptical Political Elite versus the Pro-European Public: The Case of Iceland, Scandinavian Studies 74 (2002), 349 (351). 
Misserfolge erfolgte 1999 eine Restrukturierung des linken Spektrums des Parteiensystems. Die Sozialdemokratische Partei, die Volksallianz und die Frauenliste schlossen sich zur sozialdemokratischen Allianz zusammen, gleichzeitig gründete eine Splittergruppe die isländische grüne Partei (die Links-Grünen). Die im Zuge der Finanzkrise vorzeitig angesetzten Wahlen 2009 brachten mit einer Koalition dieser beiden Parteien erstmals in der Geschichte der isländischen Republik eine linke Mehrheit an die Macht. ${ }^{19}$

\section{B. Der Sturz I: Wirtschaftscrash und Pfannenrevolution}

Am 6. Oktober 2008 wandte sich der damalige konservative Ministerpräsident Geir H. Haarde in einer Fernsehansprache an die Nation. Alle drei isländischen Großbanken waren zahlungsunfähig. Geir Haarde schloß seine Rede mit den Worten „Gott segne Island“ - spätestens da wussten alle, dass der Traum der isländischen Finanzmacht zu Ende war. ${ }^{20}$

Die isländischen Banken waren im Zuge der Liberalisierungs- und Privatisierungswelle ab Ende der 1990er Jahre privatisiert worden. 2003 waren alle großen Banken des Landes in Privatbesitz gekommen. „Die Verantwortung der Bankengeschäfte im Land übernahmen Männer, die nicht nur wenig bis gar keine Erfahrung im internationalen Bankengeschäft hatten, sondern darüber hinaus arbeiteten sie in einem Umfeld, das für Island völlig neu war.“21 Es folgte eine „Periode des außergewöhnlichen Wachstums", die isländischen Banken weiteten ihre internationalen Aktivitäten aus und wurden ein Teil der internationalen Finanzwelt, in deren Zuge es zu Schuldenanhäufungen kam. Zum Zeitpunkt des Crashs war der isländische Bankensektor etwa auf das Zehnfache des isländischen Bruttoinlandsproduktes angewachsen. Die isländische Zentralbank konnte diesem Volumen nichts entgegensetzen. ${ }^{22}$

19 Vgl. B. Pórhallsson, The Icelandic Crash and its Consequences: A Small State without Economic and Political Shelter, in: R. Steinmetz/A. Wivel (Hrsg.), Small States in Europe. Challenges and Opportunities, Farnham 2010, S. 199 (206).

20 Vgl. G.H. Haarde, Ávarp forsætisráðherra vegna sérstakra aðstæðna á fjármálamarkaði [Ansprache des Ministerpräsidenten wegen der besonderen Situation auf dem Finanzmarkt] (6.10.2008; www.forsaetisraduneyti.is, 15.7.2010); s.a. H. Guðmundsson, Wir sind alle Isländer: Von Lust und Frust, in der Krise zu sein, 2009, S. 37.

21 „Við ábyrgð á bankastarfsemi í landinu tóku menn sem ekki aðeins höfðu litla sem enga reynslu af alpjóðlegri bankastarfsemi heldur störfuðu peir einnig í umhverfi sem var alveg nýtt fyrir Íslendinga.“ Ólafsson, Efnahagsundrið (Fn. 3), S. 243.

22 Es verwundert im Nachhinein, wie weit der Weg gegangen werden konnte, bevor es zum Zusammenbruch kam, vgl. ebd.; s.a. M.J. Flannery, Iceland's Failed Banks: A Post- 
Iceland allowed a very oversized banking system to develop - a banking system that significantly outstripped the authorities' ability to act as a lender of last resort when the system ran into trouble. [...] Within a week the three banks collapsed, the króna's value dropped by more than 70 percent, and the stock market lost more than 80 percent of its value. For a small economy that is totally dependent on imports, this was a crisis of huge proportions. $^{23}$

Das Parlament erließ Notstandsgesetze, die den Eingriff in die Finanzmärkte erlaubten. Die staatliche Finanzaufsicht übernahm die Banken Glitnir, Kaupthing und die Landesbank. Die drei Banken wurden in zwei Teile getrennt, die isländischen Einlagen wurden durch Neugründungen der Banken gesichert, der ausländische Teil davon abgekoppelt. ${ }^{24}$

Viele Isländer finanzierten ihre großen Autos und neue Wohnungen mit Krediten in Fremdwährung. Im Jahr 2007 wurden auch 63 Prozent aller inländischen Unternehmenskredite in Fremdwährung vergeben ${ }^{25}$ - und damit Steuerungsmechanismen der Isländischen Zentralbank außer Kraft gesetzt. Die Finanzkrise war auch eine Währungskrise. Die isländische Krone gilt seither als nutzlos. ${ }^{26}$ Der Wertverlust führte zu großen finanziellen Problemen bei Unternehmen wie bei Privatleuten, die Kredite in Fremdwährung aufgenommen hatten und durch den Währungsverfall ihre extrem gestiegenen Kredite nicht mehr bedienen konnten. Islands Wirtschaft kam zu einem Stillstand, Fremdwährung wurde eine zeitlang nur noch für den Import von Nahrungsmitteln, Medizin und Rohöl genehmigt. Es kam nahezu zu einem Staatsbankrott. Es folgten eine Pleitewelle, steigende Arbeitslosigkeit und schwindende Kaufkraft, die Immobilienpreise verfielen. Das isländische Wirtschaftswunder, das Mitte der 1990er Jahre begonnen hatte, war vorüber. ${ }^{27}$

Als die Finanzkrise das Land traf, fand sich das Land ohne Schutz wieder. Von den USA wurde keine Hilfe angeboten - Island hatte sich jahrzehntelang militärisch und wirtschaftlich an diese angelehnt; nach dem Ende des Kalten Krieges wandten sich die USA von Island ab und schlossen 2006 auch ihre is-

Mortem, Florida 2009, S. 91 ff.

23 P. Thomsen 2008, zitiert nach $C$. Andersen, Iceland Gets Help to Recover From Historic Crisis (2.12.2008; www.imf.org, 25.7.2010).

24 Die Landesbank wird zur Neuen Landesbank, Kaupthing zu Arion und Glitnir zur Islandsbank, vgl. Flannery, Banks (Fn. 22), S. 104 ff.; s.a. Guðmundsson, Krise (Fn. 20), S. 38.

25 Vgl. R. Portes/F.M. Baldursson, The Internationalisation of Iceland's Financial Sector, Reykjavík 2007, S. 53.

26 Vgl. C. Schymik, Island auf EU-Kurs: Beitritt als Rettungsanker, SWP-Aktuell 2009/A 24.5.2009, S. 3.

27 Vgl. z.B. Pórhallsson, Crash (Fn. 19), S. 199 f. 
ländische Militärbasis. Auch Europa bot dem Nicht-EU-Mitglied keine Zuflucht. Die Suche nach einem Ausweg aus der Krise begann. Schnell tauchte die Frage auf, ob die Europäische Union einen Weg aus der Krise weisen kann. Der wirtschaftliche Aufruhr veränderte Islands Position zur EU drastisch in einer sehr kurzen Zeit. Durch die Finanzkrise wurde eine (neue) EU-Debatte im Land ausgelöst. $^{28}$

Die Wirtschaftskrise führte auch zu Umbrüchen im politischen System. In Meinungsumfragen zeigte sich eine deutlich steigende Unzufriedenheit mit der Ausgestaltung der Demokratie im Lande: 1999 waren fast 80 Prozent mit der Demokratie in Island zufrieden, 2009 nur noch knapp über 40 Prozent. $^{29}$ Das Vertrauen in die Regierung war verloren. Heftige Proteste formierten sich, dabei bildeten das Internet (Facebook) und SMS wichtige Kommunikationsmedien. Die letzten Proteste in einer vergleichbaren Heftigkeit zu den Protesten in Zuge der Krise gab es 1949 - also vor mehr als 60 Jahren - als das Land seine Neutralität aufgab und ein Gründungsmitglied der NATO wurde.

In der so genannten Kochtopf- oder Pfannenrevolution wurden - mit stetig steigenden Teilnehmerzahlen - der Rücktritt der Regierung und des Zentralbankchefs sowie Neuwahlen oder die Bildung einer Volksregierung gefordert. Viele wollten einen veränderten Regierungsstil und eine Verfassungsänderung. Die Wahlkreise sollten neu aufgeteilt, Direktwahlen sowie die Möglichkeiten für Volksabstimmungen verbessert werden - insbesondere sollte ein Teil der Wählerschaft eine Volksabstimmung einfordern können. ${ }^{30}$

Die Demonstrationen wurden immer heftiger. Ihr Höhepunkt war im Januar 2009 erreicht. Tausende Demonstranten kamen vor dem Parlament zusammen, der alljährlich von Oslo geschenkte Weihnachtsbaum wurde zerhackt und angezündet. Der Ministerpräsident sah sich mit Schneebällen und Eiern konfrontiert. Die Polizei setzte das erste Mal seit 60 Jahren Tränengas ein. Bis dahin hatte noch kein einziger Minister Verantwortung übernommen und auch in der Zentralbank oder der Bankenaufsicht gab es noch keine Rücktritte. ${ }^{31}$

28 Vgl. ebd.; s.a. V.Á. Guðjónsdóttir, Will an Economic Crisis give Iceland the Final Push?, European Union Miami Analysis 9 (2009), 3 (6).

29 Vgl. E.H. Önnudóttir/Ó.P. Harðarson, Óánægðir lýðræðissinnar: Afstaða Íslendinga til lýðræðis [Unzufriedene Demokraten: Die Einstellung der Isländer zur Demokratie], in: H.S. Guðmundsson/S.B. Ómarsdóttir (Hrsg.), Rannsóknir í félagsvísindum X [Forschungen in den Sozialwissenschaften X], Reykjavík 2009, S. 223 (227).

30 Vgl. ebd. 223 ff. Der Name der Protestbewegung entstand, weil die Demonstranten Küchengeräte zum Krachmachen benutzten.

31 Vgl. C. Ströbele, Jetzt kommt die Wut geballt heraus, Zeit online 19.2.2009. 


\section{Der Sturz II: Aufbruch und Aufarbeitung}

Ende Januar 2009 trat die Regierung in Folge der durch die Wirtschaftskrise ausgelösten Demonstrationen zurück. Die sozialdemokratische Allianz bildete mit den Links-Grünen eine Übergangsregierung. Im April 2009 kam es zu vorgezogenen Wahlen. Die Europäische Union und der Euro wurden die wichtigsten Wahlkampfthemen. Die Konservativen erlebten mit 23,7 Prozent der Stimmen ihr schlechtestes Ergebnis in der Geschichte der Partei. Die Bevölkerung gab der Unabhängigkeitspartei die Schuld. Sie war über Jahrzehnte hinweg die führende politische Kraft des Landes. Ihr Parteivorsitzender und langjähriger Ministerpräsident Davíð Oddsson galt als Anführer der Privatisierung und Liberalisierung der isländischen Wirtschaft; er hatte die Bankenprivatisierung vorangetrieben. Ab 2005 war er Chef der isländischen Zentralbank. Die Partei schnitt bei den Wahlen aber auch deshalb so schlecht ab, weil sie gegen eine EU-Mitgliedschaft votierte. $^{32}$

Im Zuge der Krise entstand auch eine neue Partei im Land, die Bürgerbewegung, welche die Stärkung der Demokratie als eine Hauptangelegenheit ansah und erweiterte Möglichkeiten für Volksabstimmungen als Grundlage der notwendigen Erneuerung der Gesellschaft forderte, „nachdem das Volk das System der repräsentativen Demokratie zusammen stürzen sah wie ein Kartenhaus“. Bei den Wahlen kam die Partei auf Anhieb auf 7,2 Prozent und errang vier Parlamentssitze - sie ist aber an internen Streitigkeiten zerbrochen und nicht mehr im Parlament vertreten. ${ }^{33}$

Die sozialdemokratische Allianz (mit 29,8 Prozent der Stimmen) und die Links-Grünen (mit 21,7 Prozent der Stimmen) waren Sieger der Wahl. Das Wahlergebnis der Links-Grünen war im Vergleich zu 2007 deutlich gestiegen die Partei ist die einzige unter den isländischen Parteien, die „keine politische Verantwortung für das Entstehen der Krise hat. ${ }^{\text {(34 }}$ Die große Koalition von Sozialdemokraten und Konservativen wurde von einer linken Regierung unter der

32 Davíð Oddsson ist heute Chefredakteur der isländischen Tageszeitung Morgunblaðið, nachdem ein Gesetz der Übergangsregierung ihn gezwungen hatte, seinen Platz in der Zentralbank zu räumen, vgl. ebd.; s.a. Schymik, EU-Kurs (Fn. 26) sowie P. Boerger, Korruption und Kollaps (13.4.2010), Dradio.de.

33 „Eftir að pjóðin hefur purft að horfa upp á kerfi fulltrúalýðræðis hrynja eins og spilaborg." Borgarahreyfingin, Umsögn Borgarahreyfingarinnar um frumvarp til laga um pjóðaratkvæðagreiðslur [Position der Bürgerbewegung um die Gesetzesvorlage über Volksabstimmungen] (28.1.2010; www.xo.is, 4.6.2010). Ein Mitglied ist heute fraktionslos und die anderen drei bildeten eine neue Fraktion, die Bewegung.

34 K. Blöndal 2009, zitiert nach Ströbele, Wut (Fn. 31). 
Ministerpräsidentin Jóhanna Sigurðardóttir abgelöst. Das Ergebnis wurde auch als ,politisches Erdbeben“ bezeichnet. ${ }^{35}$

Die sozialdemokratische Allianz machte eine EU-Bewerbung des Landes zur Voraussetzung einer Koalition, auch wenn die Links-Grünen gegen eine Bewerbung sind. In der Koalitionsvereinbarung wurden die unterschiedlichen Interessen der beiden Parteien berücksichtigt. Das Recht wurde formuliert, sich der Partei-Einstellung entsprechend in der öffentlichen Diskussion zu positionieren. ${ }^{36}$ Nach langer und erbitterter Diskussion im Parlament und einer schwierigen Abstimmung, die zeigte, dass „Politiker in Island die Mandate für die Volksvertretung eher als profilierte Einzelpersonen denn als Repräsentanten einer bestimmten Partei bekommen“", ${ }^{37}$ bewarb das Land sich im Juli 2009 um eine Mitgliedschaft in der Europäischen Union. ${ }^{38}$ Die Angliederung Islands war bis dahin einem Modus der Assoziierung gefolgt, nach dem Ende des Kalten Krieges geprägt von der Teilnahme am Europäischen Wirtschaftsraum - in dessen Folge die Kapitalfreiheit eingeführt wurde - und an Schengen. Jahrzehntelang war Island das einzige nordische und westeuropäische Land (wenn man von Mikrostaaten wie Andorra, San Marino, Liechtenstein oder Monaco absieht), das sich nie um eine Mitgliedschaft in der Europäischen Union beworben hatte.

Auf dem EU-Ratsgipfel im Juni 2010 wurde Island der offizielle KandidatenStatus zugesprochen, die Verhandlungen begannen im Juli 2010. Der Ausgang der isländischen Bewerbung ist zum jetzigen Zeitpunkt ungewiss. Im Anschluss an die Verhandlungen mit der EU ist eine Volksabstimmung vorgesehen. Diese hat keinen rechtlich verbindlichen Charakter, die Politiker werden sich aber gegen deren Ausgang nicht stellen. Eine EU-Mitgliedschaft Islands würde auch eine Änderung der Verfassung erfordern, da diese eine Abgabe von Souveränität an internationale Institutionen untersagt. Eine derartige Verfassungsänderung erfordert zwei gleich lautende Beschlüsse des Parlamentes, mit dazwischen liegenden Wahlen. ${ }^{39}$

Vgl. Schymik, EU-Kurs (Fn. 26).

36 Vgl. Samstarfsyfirlýsing rikisstjórnar [Koalitionsvereinbarung der Regierung] 2009.

37 Rubart, Stimmenfang (Fn. 12), S. 34.

3833 Parlamentsmitglieder stimmten für die Bewerbung, 28 dagegen und zwei enthielten sich der Stimme. Die einzige Partei, die geschlossen für den Antrag stimmte, war die sozialdemokratische Allianz. Alle anderen Parteien, inklusive der an der Regierung beteiligten Links-Grünen, waren über das Thema gespalten.

39 Vgl. Stjórnarskrá Íslands [Die Verfassung Islands] 1944 (Art. 79); s.a. Fréttablaðið, Ísland sækir um aðild að Evrópusambandinu [Island bewirbt sich um eine Mitgliedschaft in der Europäischen Union], 17.7.2009, 6 (6 ff.). 
Die neue Regierung will für mehr Demokratie, Transparenz, Offenheit und Informationsfluss in der isländischen Gesellschaft einstehen. Ein allgemeines Gesetz für Volksabstimmungen wurde verabschiedet - allerdings wird hier nach wie vor nicht den Bürgern die Möglichkeit gegeben, eine Volksabstimmung einzufordern. Der Gegenentwurf der Bürgerbewegung, in dem eine solche Möglichkeit vorgesehen ist, wenn mindestens zehn Prozent der Wahlberechtigten eine derartige Petition unterschreiben, konnte sich nicht durchsetzen. ${ }^{40}$

\section{Demokratie oder Markt? Das Icesave-Referendum}

Eines der größten Probleme, mit denen die neue Regierung seit Beginn ihrer Regierungszeit zu kämpfen hat, ist die Icesave-Problematik. Die so genannten Icesave-Konten waren Internetkonten, welche die isländische Landesbank ab 2006 in Großbritannien und ab 2008 in den Niederlanden eröffnet hatte. Die Konten waren in beiden Ländern nicht als selbständige Tochtergesellschaften organisiert, sondern als Auslandsfilialen der isländischen Landesbank. Aufgrund dieser Tatsache fielen die Einlagen unter den isländischen Einlagensicherungsfonds bis zu einer Höhe von 20.887 Euro pro Konto, wie im entsprechenden isländischen Gesetz im Einklang mit der geltenden EU/EWR-Richtlinie festgelegt.

Im Zuge der Krise benutzte die britische Regierung ihr Antiterrorismusgesetz, um die Anlagen isländischer Banken im Land einzufrieren. Island tauchte auf der Internet-Seite der britischen Regierung in einer Liste mit al Qaida und den Taliban auf. Dies wurde von isländischer Seite als Angriff gewertet. Die ausländischen Sparer wurden von ihren eigenen Regierungen ohne Abstimmung mit der isländischen Regierung entschädigt. Dabei wurde auf die landesspezifischen Regelungen zur Einlagensicherung zurückgegriffen. Seitdem streiten die Staaten sich mit Island um die Rückzahlungen. Der Streit geht auch um die Frage, ob die isländische Regierung gesetzlich verpflichtet ist, für den isländischen Sicherheitsfonds einzustehen. Mit der Landesbank fielen im Oktober 2008 auch die anderen beiden großen Banken Islands. Es zeigte sich, dass der Sicherheitsfonds für einen derartigen Crash nicht über genügend Mittel verfügte. Der Internationa-

40 Vgl. Samstarfsyfirlýsing ríkisstjórnar [Koalitionsvereinbarung der Regierung] 2009; Lög um framkvæmd pjóðaratkvæðagreiðslna nr. 91 [Gesetz Nr. 91 über die Durchführung von Volksabstimmungen]; Frumvarp til laga um pjóðaratkvæðagreiðslur 149, 117 mál [Gesetzesvorlage über Volksabstimmungen 149, 117. Sache]; s.a Fréttablaðið, Óvíst hvaða reglum verður kosið eftir [Unsicher, nach welchen Regeln gewählt wird], 6.1.2010, 8 . 
le Währungsfonds gewährte Island den dringend benötigten Kredit erst, nachdem das Land den Rückzahlungsforderungen zugestimmt hatte.

Im Juni 2009 wurden die ersten Vereinbarungen zwischen der isländischen und der niederländischen bzw. britischen Regierung ins isländische Parlament eingebracht. Im Verlauf der parlamentarischen Verhandlungen wurden den Vereinbarungen diverse Einschränkungen hinzugefügt, so zum Beispiel die Koppelung der Rückzahlungen an die wirtschaftliche Entwicklung des Landes. Das entsprechende Gesetz wurde im August verabschiedet und wenige Tage später vom isländischen Präsidenten Ólafur Ragnar Grímsson unterschrieben. Allerdings wurden einige der beigefügten Bedingungen von der britischen bzw. der niederländischen Regierung nicht akzeptiert. Im weiteren Verlauf wurde, nach langen und heftigen Diskussionen im isländischen Parlament im Dezember 2009, ein neues Icesave-Gesetz verabschiedet, das von den meisten Einschränkungen Abschied nahm. ${ }^{41}$

Der Icesave-Streit löste heftigen Widerstand in der isländischen Bevölkerung aus, der sich bei der Gruppe InDefence bündelte. Es handelt sich dabei um eine unparteiische, auf freiwilliger Basis agierende Gruppe, die sich im Oktober 2008 formiert hatte. Die erste Aktion der Gruppe war eine Online-Petition „Icelanders are NOT terrorists", mit der gegen die britische Anwendung des Antiterrorismusgesetzes protestiert wurde. Über 83000 Unterschriften kamen zusammen, welche die Gruppe im März 2009 dem britischen Parlament übergab. InDefence startete eine neue Unterschriftensammlung im Internet, mit der der Präsident dazu aufgerufen wurde, das Gesetz nicht zu unterschreiben. Bei der Unterschriftensammlung mit dem Aufruf an den Präsidenten kamen 56089 Unterschriften zusammen, die dem Präsidenten am 2. Januar 2010 übergeben wurden. Dies entspricht fast einem Viertel aller Wahlberechtigten in Island. Der isländische Präsident verweigerte dem Gesetz seine Unterschrift und ermöglichte so eine Volksabstimmung. ${ }^{42}$

Die isländische Regierung reagierte mit Enttäuschung auf die Entscheidung des Präsidenten. Die Ministerpräsidentin verwies darauf, dass die Entscheidung das Image des Landes weiter beschädigen und die Hoffnungen auf eine Mitgliedschaft in der Europäischen Union zerstören könnte. „Unsicherheit oder Spannungen in den finanziellen Beziehungen mit anderen Ländern können unvorhergesehene, weitreichende und sehr schädliche Konsequenzen für unsere Gesellschaft haben.“ Die Entscheidung verzögere den wirtschaftlichen Wiederaufbau

41 Vgl. z.B. C. Schymik, Islands Volksabstimmung über Icesave, SWP-Aktuell 14.2.2010, S.

$1 \mathrm{ff}$.; Indefence, Factsheet (www.indefence.is, 15.4.2010).

42 Vgl. Indefence, About (www.indefence.is, 15.4.2010). 
des Landes, den dringend benötigten Kredit vom Internationalen Währungsfonds und den nordischen Ländern. Ferner sah sie die Gefahr möglicher negativer Auswirkungen auf die Währung. ${ }^{43}$

Auch der sozialdemokratische Außenminister Össur Skarphéðinsson kritisierte mit harten Worten die Entscheidung des Präsidenten:

Ich halte das für eine völlig falsche Entscheidung des Präsidenten und denke, dass sie auf einer extrem falschen Einschätzung der wirtschaftlichen Folgen basiert. [...] Die ausländischen Reaktionen sind deutlich härter, als ich erwartet hatte, und wir müssen alles uns mögliche unternehmen, damit die Verträge, die wir geschlossen haben, wie über den Kredit der nordischen Länder und den Wirtschaftsaufbau mit dem IWF, halten. Das ist das Schlüsselmoment dafür, dass die Entscheidung des Präsidenten nicht das Vertrauen, das das Volk und die Regierung gemeinsam aufgebaut haben, zerstört. ${ }^{44}$

Die ersten Reaktionen auf das Veto des isländischen Präsidenten waren negativ: Es herrschte eine große Unsicherheit über die nächsten Schritte, vor allem im Hinblick auf den Kredit des Internationalen Währungsfonds. Großbritannien und die Niederlande reagierten mit harten Worten. Vielfach wurde die Entscheidung des Präsidenten im Ausland als eine generelle Ablehnung Islands, seine Schulden zu begleichen, interpretiert. Dies beschädigte das internationale Ansehen des Landes. $^{45}$

Die britische Rating-Agentur Fitch reagierte auf die Entscheidung des Präsidenten mit der Herabstufung der Kreditwürdigkeit Islands. Der Direktor der Agentur, Paul Rawkins, betonte, dass in Folge der Entscheidung eine erneute Welle innenpolitischer, wirtschaftlicher und finanzieller Unsicherheit kreiert werde.

Auch bedeutet dies einen signifikanten Rückschritt in den isländischen Bemühungen, normale finanzielle Beziehungen zum Rest der Welt aufzubauen. Der negative Ausblick

43 „Óvissa eða uppnám í fjármálalegum samskiptum við önnur ríki getur haft ófyrirsjáanlegar, viðtækar og mjög skaðlegar afleiðingar fyrir íslenskt samfélag.“ Jóhanna Sigurðardóttir 2010, zitiert nach Fréttablaðið, Tvísýnt um endurreisnaráætlun [Unsicherheit über den Wiederaufbauplan], Fréttablaðið 6.1.2010, 6; s.a. Fréttablaðið, Óvissa og uppnám eftir synjun forseta [Unsicherheit und Unruhe nach dem Veto des Präsidenten], Fréttablaðið 6.1.2010, 1.

44 „Ég tel petta kolranga ákvörðun hjá forsetanum og held að hún byggi á mjörg rangri greiningu á mögulegum efnahagslegum afleiðingum. [...] Viðbrögðin erlendis hafa verið mun harkalegri en ég átti von á, en við purfum að gera allt sem hægt er til að sjá til pess að samningar sem við höfum gert, eins og samningar um Norðurlandalán og efnahagsáætlunina með Alpjóðagjaldeyrissjóðnum, haldi. Баð er lykilatriði til að ákvörðun forsetans rústi ekki pað traust sem pjóðin og ríkisstjórnin höfðu í sameiningu verið að byggja." Össur Skarphéðinsson 2010, zitiert nach ebd.

45 Vgl. Fréttablaðið, Segja bjóðina neita að borga [Sagen, dass sich das Volk weigert zu zahlen], Fréttablaðið 6.1.2010, 1; s.a. Schymik, Icesave (Fn. 41). 
spiegelt die Möglichkeit weiterer Isolation Islands auf den internationalen Finanzmärkten wider und die Gefahr, dass der jetzige Plan für Stabilität und Wiederaufbau der Wirtschaft misslingt. ${ }^{46}$

Der Präsident Islands verwies in seiner Erklärung, die er seiner Entscheidung beifügte, auf den öffentlichen Widerstand gegen das Gesetz.

It is the cornerstone of the constitutional structure of the Republic of Iceland that the people are the supreme judge of the validity of the law. [...] It is then the responsibility of the President of the Republic to ensure that the nation can exercise this right. [...] Now the people have the power and the responsibility in their hands. ${ }^{47}$

In verschiedenen Interviews erläuterte er seine Einstellung genauer. Er verwies auf die Petition und den Wunsch der Bevölkerung, in einer Volksabstimmung über das Gesetz entscheiden zu dürfen. Er erinnerte daran, dass die Entwicklung des westlichen Erbes auf zwei Pfeilern beruht, neben dem Markt sei dies die Demokratie. Der Markt habe die Oberhand über die Demokratie bekommen. Er habe sich im Konflikt zwischen Finanzen und Demokratie für die Demokratie entschieden. $^{48}$

Traditionell hat der Präsident Islands eine unpolitische Rolle inne. 1993 entschied sich die damalige Präsidentin Vigdís Finnbogadóttir entgegen dem herrschenden Meinungsbild, den Vertrag über den Europäischen Wirtschaftsraum zu unterzeichnen und so das von vielen geforderte Referendum zu verhindern. Damals hatten 34.000 Wähler (das sind etwa 19 Prozent der Wählerschaft bzw. mehr als zehn Prozent der Bevölkerung) eine Petition gegen den EWR-Vertrag unterschrieben, in der ein Referendum gefordert wurde. Vigdís Finnbogadóttir ließ schließlich ihrer Unterschrift eine Erklärung folgen. Dies war damals ein sehr ungewöhnlicher Schritt. In ihrer Erklärung betonte sie die traditionell unpolitische Rolle des Präsidenten, der zur Einheit der Nation und zu einem nationalen Konsensus beizutragen habe. „Kein Präsident ist eingeschritten gegen legale

46 „Hún táknar einnig mikinn afturkipp í viðleitni Íslands til að endurreisa eðlileg fjármálasamskipti við umheiminn. Petta neikvæða útlit heldur áfram að endurspegla [...] möguleikana á meiri einangrun Íslands á alpjóðlegum fjármálamörkuðum og hættuna á pví að núverandi áætlun um efnahagslegan stöðugleika og endurreisn muni kollsteypast.“ P. Rawkins 2010, zitiert nach Fréttablaðið, Ísland í ruslflokk og í einangrun [Island in Müll-Gruppe und Isolation], Fréttablaðið 6. Januar 2010, 4. Von isländischer Seite wurde dies heruntergespielt. „Diese Entscheidung ändert nichts“, war aus Universitätskreisen zu hören, „und man darf auch nicht vergessen, dass es sich bei Fitch um ein britisches Unternehmen handelt.“ („,Pessi ákvörðun [...] breytir engu [...]. Раð er Breti sem talar fyrir fyrirtækið.") Lektor Ó. Ísleifsson 2010, zitiert nach ebd.

47 Ó.R. Grímsson, Declaration by the President of Iceland; vgl. auch Fréttablaðið, Óvissa og tóm í stjórnarskránni [Unsicherheit und Leere in der Verfassung], 6.1.2010, 10.

Vgl. Ó.R. Grímsson 2010, zitiert nach Lorie, President (Fn. 1). 
Entscheidungen des demokratisch gewählten Parlaments. “49 2004 verweigerte Ólafur Ragnar Grímsson dem sehr umstrittenen Mediengesetz seine Unterschrift. Damals kam es aber nicht zu einer Volksabstimmung, da die Regierung das Gesetz zurückzog. ${ }^{50}$

Verfassungsrechtlich ist das isländische Icesave-Referendum unumstritten, da - wie bereits erwähnt - nach Artikel 26 der isländischen Verfassung in Folge eines Vetos des Präsidenten ein Referendum einberufen werden muss. Ólafur Ragnar Grímsson ist der erste isländische Präsident, der mit seiner Verweigerung einer Unterschrift ein Referendum ermöglicht hat.

Die Regierung versuchte in der Zeit vor dem Referendum die Bedeutung der Abstimmung herunterzuspielen. Sie stellte es sogar als Geldverschwendung dar. Jóhanna Sigurðardóttir argumentierte, die Abstimmung sei bedeutungslos, da in den nach dem Veto des Präsidenten neu aufgenommenen Verhandlungen bereits ein besseres Angebot von den Briten und Holländern vorgelegt wurde (auf das man sich aber nicht einigen konnte). Auch Steingrímur Sigfússon betonte die Sinnlosigkeit der Abstimmung. Bei einem Nein-Votum sei das Problem nicht gelöst. Er empfand es als schmerzlich, dass die erste Volksabstimmung in der Geschichte der Republik in diesem Zusammenhang stattfindet. ${ }^{51}$

Da kein Gesetz zur Durchführung der Volksabstimmung existierte, wurde für das Icesave-Referendum ein Gesetz verabschiedet, das größtenteils die geltenden Parlamentswahlgrundsätze anwendete (Wahlberechtigung und Wahlkreise, Entscheidung einer einfachen Mehrheit). ${ }^{52}$ Vor dem Referendum wurden in allen

49 „Enginn forseti hefur gripið fram fyrir hendur á lýðræðislega kjörnu Alpingi sem tekið hefur ákvarðanir sínar með lögmætum hætti.“ V. Finnbogadóttir, Yfirlýsing forseta Íslands [Erklärung der Präsidentin Islands], Morgunblaðið 14. Januar 1993, 26; siehe dazu auch B. Pórhallsson, Evrópustefna íslenskra stjórnvalda: Stefnumótun, átök og afleiðingar [Die Europapolitik isländischer Regierungen: Bildung, Konflikte und Folgen], in: V. Ingimundarson (Hrsg.): Uppbrot hugmyndakerfis. Endurmótun íslenskrar utanríkisstefnu 1991-2007 [Umbruch des Ideensystems. Die Neubildung der isländischen Außenpolitik 1991-2007], Reykjavík 2008, S. 67 (88 ff.).

50 Vgl. G.H. Kristinsson, Íslenska stjórnkerfið [Das isländische politische System], 2. Aufl. Reykjavík 2007, S. 154 f.; s.a. R. Jackson, Should the King have a Crown?, Grapevine 3/2004, 10 f. Von der damaligen Opposition waren mehrere Politiker der Meinung, dass es im Widerspruch mit der isländischen Verfassung stehe, über das Gesetz nicht in einer Volksabstimmung entscheiden zu lassen, vgl. Fréttablaðið, Ógilding lögleg en pólitískt ólíklegt [Annullierung legal aber politisch unwahrscheinlich], Fréttablaðið 6.1.2010, 8.

51 Vgl. z.B. H.M. Pétursson, Gæti dregið til úrslita á næsta sólarhring [Entscheidung in den nächsten 24 Stunden möglich] (2.3.2010; www.visir.is, 2.3.2010); Morgunblaðið, Jóhanna ætlar ekki á kjörstað [Jóhanna will nicht abstimmen] (5.3.2010; www.mbl.is, 5.3.2010).

52 Vgl. Lög nr 4/2010 um framkvæmd pjóðaratkvæðagreiðslu um gildi laga nr 1/2010 
Haushalten Informationsbroschüren verteilt, vom Rechtsinstitut der Universität auf Wunsch des Innenministeriums verfasst.

Die Gruppe InDefence startete im Februar 2010 eine offizielle NeinKampagne mit Treffen und Pressekonferenzen überall im Land - bis dahin hatte die Gruppe sich hauptsächlich über das Internet artikuliert. In den wieder aufgenommenen Verhandlungen mit den Briten und den Niederländern wurden vorteilhaftere Bedingungen ausgehandelt, auf die man sich aber nicht einigen konnte. Bis zuletzt war die Möglichkeit gegeben, dass es zu einer Einigung kommen könnte und dann das Referendum nicht stattfinden würde. Am 6. März kam es dann aber doch zur ersten Volksabstimmung in der Geschichte der isländischen Republik. $^{53}$

Das Icesave-Referendum behandelte entgegen anders lautenden Medienberichten nicht die Frage, $o b$ Island seine Schulden begleichen will. Die Zahlung wurde von der isländischen Regierung mehrfach zugesichert. Umstritten sind die Rückzahlungsmodalitäten, die zwischen der isländischen und der britischen bzw. niederländischen Regierung ausgehandelt wurden und die vor allem aufgrund hoher Zinsverpflichtungen einen Proteststurm auslösten. ${ }^{54}$

Im isländischen Referendum wurden die ausgehandelten Bedingungen der Rückzahlung mit 93,2 Prozent der Stimmen abgelehnt. Nur 1,8 Prozent stimmten dem Gesetz zu, 5 Prozent der Stimmen waren ungültig. Die Wahlbeteiligung lag bei 62,7 Prozent. Unter denen, die nicht an der Abstimmung teilnahmen, waren auch die isländische Ministerpräsidentin Jóhanna Sigurðardóttir und der Finanzminister Steingrímur Sigfússon. Beide hatten dies schon im Vorfeld angekündigt. $^{55}$

Kritiker des Referendums verwiesen auf die negativen Reaktionen im Ausland, insbesondere den internationalen Imageverlust. Sie stellten auch den Sinn des Referendums in Frage, da zum Zeitpunkt der Abstimmung von den Briten und den Niederländern bereits neue, für Island vorteilhaftere Konditionen ange-

[Gesetz Nr. 4/2010 über die Durchführung der Volksabstimmung über das Gesetz Nr. $1 / 2010]$.

53 Bis zur Gründung der Republik 1944 hatte es sechs Volksabstimmungen gegeben: 1908 über das Einfuhrverbot von Alkohol, 1916 über Pflichtarbeit für die Gesellschaft, 1918 über die Verbindung mit Dänemark, 1933 über die Aufhebung des Alkoholeinfuhrverbotes, 1944 über die Verfassung und die Aufhebung der politischen Verbindung mit Dänemark, vgl. Kristinsson, Próun (Fn. 15), S. 56; s.a. Kristinsson, Stjórnkerfið (Fn. 50), S. $150 \mathrm{f}$.

54 Für eine etwas andere Einschätzung vgl. Schymik, Icesave (Fn. 41), S. 2.

55 Vgl. zu den Ergebnissen des Referendums z.B. Dómsmálaraðuneyti, Auglýsing um niðurstöðu pjóðaratkvæðagreiðslu [Information über den Ausgang der Volksabstimmung], (www.kosning.is, 10.4.2010). 
boten wurden. Neben die Gefahr negativer wirtschaftlicher Auswirkungen trete auch die Gefahr einer politischen Isolation des Landes.

Der Icesave-Streit hat sich auch negativ auf die EU-Bewerbung des Landes ausgewirkt. Zwar wurde wiederholt betont, dass es sich dabei um zwei voneinander getrennte Sachverhalte handele. In der Wahrnehmung der isländischen Bevölkerung unterstützte aber die EU den harten Kurs der Briten und Niederländer, dies führte innerhalb der Bevölkerung zu einer Anti-EU-Stimmung. Es ist anzunehmen, dass sich Island schnell aus der Krise herausarbeiten wird, und dies höchstwahrscheinlich ohne Hilfe der EU.

Ich sage voraus, dass Island in absehbarer Zukunft nicht in die EU eintreten wird. [...] Das würde vielleicht dann am ehesten geschehen, wenn die wirtschaftliche Situation sich weiter verschlechtert. Dann könnten die Isländer in einem verrückten Moment Ja sagen, aber an einem normalen Tag werden sie Nein sagen. ${ }^{56}$

Die Bevölkerung sieht sich von der EU (über den Internationalen Währungsfonds) gezwungen, eine ,moralische“ Schuld auf sich zu nehmen, deren rechtlicher Status ungeklärt ist und die sie verpflichtet, für das verantwortungslose Handeln einzelner Banker geradezustehen. Hier zeigt sich nicht zuletzt eine fehlerhafte europäische Gesetzgebung, die nicht für eine derartige Krise ausgelegt wurde. $^{57}$

\section{E. Jüngste Entwicklungen: Neuanfang?}

Der Icesave-Streit ist zum jetzigen Zeitpunkt im Sommer 2010 noch nicht gelöst. Die Verhandlungen sind vor kurzem wieder neu aufgenommen worden. Die isländische Regierung hat ihre Rückzahlungsverpflichtung im Zuge der zweiten Prüfung durch den IWF bestätigt. Von der ESA, der Aufsichtsbehörde der EFTA, wurde in einem Statement vom Mai 2010 Island dazu aufgefordert, seine Schulden zu bezahlen. ${ }^{58}$

56 „Ég spái pví að Ísland gangi ekki í ESB í fyrirsjáanlegri framtíð,“ [...] Pað væri pá helst ef efnahagsástandið héldi áfram að versna. „,á gætu Íslendingar í augnabliks geðveiki átt pað til að segja já, en á venjulegum degi munu peir segja nei.“ E.B. Einarsson 2009, zitiert nach Fréttablaðið, Segir tóma blekkingu að Noregur standi utan ESB [Sagt, es sei ein Schwindel, dass Norwegen außerhalb der EU stehe], Fréttablaðið 25.9.2009, 12.

57 Vgl. J.B. Hannibalsson, Iceland and the Current Economic Crisis - Political Implications and the Way Forward (10.11.2009; www.evropa.is/2009/11/10/iceland-and-the-currenteconomic-crisis, 21.4.2010).

58 Vgl. z.B. Fréttablaðið, Sampykkja „eðlileg“ vaxtakjör [Zustimmung zu „vernünftigen“ Zinsbedingungen], Fréttablaðið 19.4.2010, 1; J.H. Halldórsson, Íslandi ber að greiða Icesave [Island muss Icesave bezahlen] (26.5.2010), (www.visir.is, 15.7.2010); 
Kleinstaaten können sich prinzipiell aufgrund ihrer kleinen Bürokratie und der kurzen Wege schneller von Krisen erholen als große Staaten. Die wirtschaftliche Situation im Land ist 2010 besser, als man erwartet hatte. Im Zuge der Aufarbeitung der Krise ist in Island im April 2010 ein Untersuchungsbericht mit über 2.300 Seiten erschienen, der die Hintergründe der Krise beleuchtet. Der Bericht zeigt, dass die Verantwortung für die Finanz- und Währungskrise innerhalb des Landes zu suchen ist. Die vermehrten Freiheiten im Finanzsektor wurden von mangelnden Kontrollmechanismen begleitet. Es gab drastische Versäumnisse bei der Finanzaufsicht, der Zentralbank, der Regierung und beim Parlament sowie bei den Medien. Inzwischen ist es zu ersten Festnahmen und Anklagen im Land gekommen. $^{59}$

Island hat aber auch damit zu kämpfen, dass die politische und wirtschaftliche Elite klein und daher schwer austauschbar ist - es hat sich gezeigt, dass die Krise etwa von 30 Personen verursacht wurde. Bei den Kommunalwahlen im Mai 2010 zeigte sich vor allem bei den Wählern in der Hauptstadt Reykjavík der Protest gegen die Verantwortlichen der Finanzkrise. In Reykjavík ging die im Dezember 2009 neu gegründete Beste Partei des Komikers Jón Gnarr als Sieger aus den Wahlen hervor. Sie bekam fast 35 Prozent der Stimmen und sechs von 15 Sitzen im Stadtrat, obwohl sie so gut wie keine Werbung geschaltet und auch nur sehr geringe finanzielle Mittel zur Verfügung hatte. Allerdings hat sie einen Wahlkampfsong produziert, der ihr fast schon zu internationaler Berühmtheit verhalf. Der Wahlsieg einer Partei, ,deren Programm es ist, kein Programm zu haben und andere Parteien zu parodieren, [gilt als] ein Triumph der Satire über die Realität. “60 Die Beste Partei und die Sozialdemokraten einigten sich auf eine Koalition, Jón Gnarr ist der neue Bürgermeister von Reykjavík.

In Island hat die internationale Finanzkrise früh und heftig zugeschlagen. In der Folge entstand eine vielfältige Demokratiebewegung, die zu einer Veränderung der politischen Verhältnisse führte und letztlich auch mit Hilfe eines Referendums erneute Verhandlungen über die aus der Finanzkrise entstandenen Schulden erzwang. Der Ausgang ist noch offen. Auch die Frage, ob Island der EU beitreten wird oder nicht, ist noch nicht entschieden.

Fréttablaðið, Aðildarviðræður tengdar Icesave [Beitrittsgespräche abhängig von Icesave], Fréttablaðið, 19.6.2010, 8.

59 Vgl. Ólafsson, Efnahagsundrið (Fn. 3); für eine englische Zusammenfassung der wesentlichen Ergebnisse des Untersuchungsberichtes Rannsóknarnefnd, Executive Summary (http://sic.althingi.is, 10.6.2010).

60 H.M. Broder, Reykjavik erwartet den Staats-Streich (28.5.2010), Spiegel online. Die Wahlbeteiligung lag bei 73,4 Prozent in Reykjavík, vgl. Morgunblaðið, Kosningar [Wahlen] 2010, (www.mbl.is/mm/frettir/kosningar, 10.7.2010). 